\title{
Ensayo de una «anatomía» de la República de las Letras. Nueva España, siglo XVIII
}

\section{An Essay on the "Anatomy» of the Republic of Letters. New Spain, 18th Century}

OLIVIA MORENO GAMBOA

Universidad Nacional Autónoma de México

oli_moreno@hotmail.com

\section{RESUMEN}

Este artículo recupera viejas y nuevas propuestas de la historia cultural y la historia literaria aplicadas al estudio de la República de las Letras en la Francia prerrevolucionaria; trasladando estas al espacio de la Nueva España con la finalidad de trazar la "anatomía» o el perfil socioprofesional de los autores novohispanos. A lo largo del siglo XVIII, esta comunidad experimentó cambios significativos en su composición, relacionados en cierta medida con la secularización eclesiástica y el reformismo borbónico. Con estas páginas, se busca contribuir al debate sobre el impacto de la Ilustración en el ámbito colonial hispánico.

Palabras clave: República de las Letras, autores novohispanos, imprenta en México, Ilustración, historia cultural.

\section{ABSTRACT}

This article draws on old and recent concepts from cultural and literary history as applied to the Republic of Letters in pre-revolutionary France, transferring them to the history of New Spain, with the goal of tracing the "anatomy" or social and professional profile of Mexican authors. During the 18th century, 
this community experienced important changes in its composition, related to some extent to ecclesiastical secularization and the Bourbon Reforms. This article seeks to contribute to the debate on the impact of the Enlightenment on colonial Spanish America.

Keywords: Republic of Letters, Mexican authors, Printing Press in Mexico, Enlightenment, Cultural history.

Clinterés por ciertas manifestaciones y figuras relevantes de la cultura lugar a trabajos particulares, que arrojan luz sobre la consolidación y la transformación de la República de las Letras en la época colonial. Sin embargo, hasta el momento, no existe una línea historiográfica dedicada de manera puntual al estudio de la república literaria en el ámbito novohispano, como las que se han desarrollado en Francia, Inglaterra, Alemania, Italia, y que se busca impulsar en Espańa. Por ello, la obra de Magdalena Chocano Mena, La fortaleza docta, representó en su momento un importante esfuerzo de renovación historiográfica y una invitación a elaborar visiones de conjunto de las comunidades letradas en la América española. ${ }^{1}$ Enrique González González, especialista en universidades coloniales, retomó dicha invitación y arrancó una investigación sobre los letrados novohispanos, que poco después me animó a proseguir. ${ }^{2}$

Así surgió Las letras y el oficio. Novohispanos en la imprenta. México y Puebla. Siglo XVIII, ${ }^{3}$ un trabajo en el que me propuse mostrar la relación entre los hombres de letras y la imprenta local a lo largo del siglo que suele identificarse con el reformismo, la secularización y la Ilustración. Con tal propósito, realicé dos tipos de análisis cuantitativos, cuyos resultados dieron sustento a mis reflexiones: uno bibliométrico de los impresos (de corte literario) publicados en Nueva España entre 1701 y

1 Chocano 2000.

2 Enrique González publicó los primeros resultados de esa investigación en 2011, véase la bibliografía.

3 Moreno 2018. 
1821, y uno prosopográfico de sus «autores», es decir, de los individuos que estamparon su nombre en las portadas de esos impresos.

En la medida en que las repúblicas literarias de la época moderna se definieron cada vez más por su relación con el impreso, ${ }^{4}$ me fue posible proponer un perfil de la república novohispana de las letras a partir de dicho análisis. Este perfil, como otros realizados para otros periodos y geografías, fue resultado de la clasificación de los escritores en categorías socioprofesionales. Esto me permitió detectar cambios y continuidades en la composición de la comunidad letrada y en sus prácticas de publicación, esto es, en su uso la imprenta. También pude observar a gran escala el ritmo y la intensidad de la secularización de dicha comunidad. Sin embargo, estoy consciente de que las conclusiones que expuse en las Letras y el oficio derivaron en buena medida de la construcción de una serie de perfiles. Por ello, me he preguntado hasta qué punto el carácter maleable de las categorías socioprofesionales —elaboradas a partir de la selección de determinadas fuentes y enfoques metodológicos- diversifica el perfil de la república literaria. A modo de experimento, en estas páginas propongo una clasificación más precisa de los autores laicos, uno de los tres segmentos en el que originalmente agrupé a los escritores novohispanos. Este ejercicio de reclasificación y su comparación con otras geografías literarias siguen de cerca la propuesta que hizo Robert Darnton en su artículo «The Literary Revolution of 1789».5

\section{UNA «REVOLUCIÓN» LITERARIA A FINALES DEL ANTIGUO RÉGIMEN}

Desde hace ya varias décadas, especialistas de la literatura, la sociología y la historia cultural se vienen ocupando de los autores que integraron la República de las Letras en el periodo moderno. De meros artífices de textos manuscritos, marginados del proceso de la edición, los autores resurgieron como piezas claves del circuito de la comunicación escrita en el mercado editorial, gracias los trabajos de Arthur Simons Collins, J. W. Saunders y Dustin Griffin en Inglaterra, y a los de Maurice Pellisson,

\footnotetext{
4 Álvarez Barrientos 2006: 23.

5 Darnton 2003b.
} 
Pierre Bourdieu, Alain Viala, Daniel Roche, Roger Chartier en Francia y Robert Darnton en Estados Unidos, entre otros.

Hoy estos estudios son particularmente fecundos para el periodo de las Luces, en virtud de la creciente importancia política y cultural de filósofos y enciclopedistas, y de su protagonismo en la cultura impresa. En México, son más conocidas las aportaciones historiográficas de Darnton y Chartier sobre la Francia prerrevolucionaria. Ambos han reflexionado sobre el perfil sociocultural de la república literaria, sobre la relación de los escritores con el poder monárquico, sus prácticas y espacios de sociabilidad, su profesionalización y, en el caso particular de Darnton, sobre su participación en el negocio editorial, particularmente el clandestino. ${ }^{6}$

Desde esta perspectiva, el estudio de los escritores permite profundizar en los múltiples procesos de difusión del pensamiento moderno, lo que ha llevado de manera casi natural a interrogarse sobre el proceso de laicización/desacralización del campo literario, problema estrechamente relacionado, por un lado, con el declive de la teología como fuente indiscutible e inagotable de saber y, por el otro, con el avance de la Ilustración, a lo que deben añadirse diversas consideraciones sobre otros fenómenos socioculturales igualmente significativos.

Como es bien sabido, Darnton ha ido más allá de la interpretación tradicional que adjudicaba a las obras filosóficas un impacto decisivo en el desarrollo de las «revoluciones burguesas». Al sumergirse en los archivos de la Sociedad Tipográfica de Neuchâtel, descubrió los bajos fondos de la República de las Letras y, en ellos, a centenares de autores medianos que desde la clandestinidad escribían y editaban novelas, periódicos y libelos subversivos en los que denunciaban los vicios y la decadencia del clero y la aristocracia, al tiempo que proponían un orden social y moral distinto al que entonces prevalecía. ${ }^{7}$ Así, según Darnton, la baja literatura que circuló en años previos a la revolución de 1789 ayudó a

6 Darnton 2002; Chartier 1995.

7 Darnton 2014: 178-180. 
popularizar ciertas ideas ilustradas, poco accesibles fuera de los salones burgueses y de las academias científicas y literarias. ${ }^{8}$

Chartier, por su parte, se mostró más suspicaz respecto de la influencia de los «libros filosóficos» en el origen de la revolución. Invitó, por el contrario, a pensar en un proceso inverso, en el que una transformación previa de la sensibilidad y de las prácticas culturales condujo a una paulatina desacralización (del rey, del clero e incluso del libro como objeto mismo), que hizo accesible y atractiva ese tipo de literatura. ${ }^{9}$

Visto el asunto de este lado del Atlántico, un aspecto que llama fuertemente la atención sobre la república literaria de la Francia ilustrada es el peso de los autores laicos: del tercer estado frente a las órdenes "privilegiadas", nobleza y clero. ${ }^{10} \mathrm{Y}$ es que en la América española, los escritores seglares fueron siempre minoría, si bien es verdad que plumas como las de José Joaquín Fernández de Lizardi y Carlos María Bustamante hicieron más por la transformación de la cultura impresa a finales del régimen colonial que generaciones completas de frailes y curas panegiristas. En Francia, el ascenso de los médicos y abogados de la baja burocracia y de los "gremios intelectuales» presionó a favor de una relativa apertura de la República de las Letras y, en consecuencia, de su laicización. ${ }^{11}$. De ahí que Darnton optara por describir a la Francia literaria de la víspera de la revolución como una "élite mezclada». ${ }^{12}$

Pero el aumento de los laicos procedentes de la pequeña burguesía no debe llamar al engaño sobre la profesionalización de las letras, cuestión

8 Darnton 2003a. A partir de estudios de caso, los tres primeros ensayos de esta obra reflexionan sobre los autores y la República de las Letras en Francia: «La baja literatura en la ilustración tardía», «Un espía en grub stree»t y «Un panfletista a la fuga».

9 Chartier 1991: 81-106.

${ }^{10}$ Paul Benichou, historiador y crítico de la literatura francesa, había apuntado en Le sacre de l'écrivain 1750-1830 que el debilitamiento del "poder espiritual» de la Iglesia fue una condición necesaria para el advenimiento de un nuevo "sacerdocio laico», protagonizado por el poeta romántico, quien habría destronado al filósofo como guía espiritual y moral de la burguesía, así como este lo había hecho con el teólogo medio siglo atrás (Benichou 2006: 22-73).

${ }^{11}$ Véase el anexo.

${ }^{12}$ Darnton 2003b: 173. 
que ha sido central en las investigaciones desde hace un siglo. ${ }^{13} \mathrm{Y}$ esto porque, efectivamente, las condiciones bajo las cuales operaba el negocio editorial en Francia impedían la profesionalización del escritor. Como señaló Darnton: «La falta de un efectivo derecho de autor, el predominio de la piratería, la inexistencia de regalías, las asfixiantes limitaciones del sistema de censura y las prácticas monopólicas del gremio de los libreros hacían imposible vivir de la pluma». ${ }^{14} \mathrm{~A}$ esto se debe añadir que entre los honnêtes gens de lettres y los gentlemen amateurs aún prevalecía la idea (o el ideal) de que la escritura era un ejercicio de recreación personal, por lo que rechazaban hacer de la literatura un medio de ganancia y subsistencia económica.

En un sugerente artículo sobre el caso británico, Griffin cuestionó varios lugares comunes sobre la figura del autor y su profesionalización. Por principio, hizo una crítica a la teoría de Michel Foucault, muy aceptada hasta hace unos años, en el sentido de que la figura del autor surgió durante el siglo XVIII, cuando este se convirtió formalmente en una «categoría legal», es decir, en alguien a quien el Estado podía responsabilizar y castigar por sus escritos. Sin embargo, Griffin aclaró con razón que en Inglaterra la mayoría de los autores vendían inmediatamente sus derechos a un librero y que, una vez vendidos, dejaban de considerarse propietarios legales de sus obras, tal como sucedía también en el ámbito hispano. Así, el copyright, reconocido en 1710, fue en realidad el derecho exclusivo de libreros e impresores para reproducir y vender una obra, no «a key to authorial self-images». ${ }^{15}$

${ }^{13}$ En 1911, Maurice Pellisson publicaba en Francia un estudio pionero -«D'ordre moral, sourtout d'ordre social»- sobre Les hommes de lettres au XVIIIe siècle, con el que intentaba mostrar los "progresos» de este colectivo de "nación» francesa para asegurarse "la considération sociale à leur profession et à devenir par là plus capables de diriger l'esprit public» (ver Avant Propos). Por su parte, A. S. Collins publicó en la década de 1920 Authorship in the Days of Johnson: Being a Study of the Relation Between Author, Patron, and Public, 1726-1780 (1927); y The Profession of Letters: A Study of the Relation of Author to Patron, Publishers, and Public, 1780-1832 (1728).

${ }^{14}$ Darnton 2003b: 168.

${ }^{15}$ Griffin 2009: 134. Otra revisión de la función-autor de Foucault en Chartier 2000: $89-105$. 
Así, la conclusión a la que han llegado Darnton y otros especialistas es que a finales del ancien régime no había «escritores de la variedad moderna»; esto es, «los que viven de su pluma como intelectuales independientes». En Francia — dice el historiador norteamericano- un grupo marginal, sin estamento socioocupacional definido, ausente en la bibliografía de La France littéraire, se ocultó en la Grub Street para vivir una vida literaria mediocre y miserable que solo es posible observar realizando un «análisis microscópico de los textos» que complemente el de los perfiles sociológicos, como el que se propone en seguida. ${ }^{16}$

\section{EL OFICIO DE LAS LETRAS EN LA NUEVA ESPAÑA DEL SIGLO XVIII}

¿Es posible ensayar la metodología de Darnton en el espacio novohispano? Personalmente, creo que sí, dado que se cuenta con instrumentos para ello. En concreto, me refiero a los catálogos bibliográficos de José Toribio Medina (1852-1930) para las ciudades de México y Puebla de los Ángeles, y la Biblioteca Hispanoamericana Septentrional de José Mariano Beristáin de Souza (1756-1817), que ofrece información biográfica y literaria de 3687 autores de impresos y manuscritos aparecidos entre 1539 y 1815 , año de su publicación. ${ }^{17}$

En dichos repertorios, Medina ofreció registros bibliográficos de los impresos que iba localizando en bibliotecas y archivos. Gracias a ello, se pueden construir series de datos más o menos uniformes que, completados con los que proporciona Beristáin, permiten reconstruir lo que podría llamarse una «anatomía» de la República de las Letras en la Nueva Espańa del siglo XVIII, y comenzar a formular preguntas sobre la relación de los escritores con la imprenta, un medio de comunicación y opinión muy restringido en la América hispana.

Pero antes de mostrar sintéticamente el resultado de mis investigaciones, es importante mencionar que también en Espańa se han realizado acercamientos de tipo sociológico sobre los autores del setecientos; los cuales, sin embargo, parecen no haber tenido continuidad. En un primer

\footnotetext{
${ }^{16}$ Darnton 2003b: 175-176.

${ }^{17}$ Beristáin 1981, 1: XVIII.
} 
balance, el hispanista francés Jean-Marc Buigues habló de una población de 7593 autores que publicaron en total de 19,549 nuevas obras en castellano a lo largo del siglo XVIII. Considerando que la producción de las prensas ibéricas — concentradas en Madrid, Barcelona, Valencia y Sevilla - era muy baja en comparación con la francesa, ${ }^{18}$ se tiene en el caso espańol una «sobrepoblación» de autores. Aunque preliminares, estos resultados permitieron hablar de un crecimiento de la población literaria y de su tendencia a la secularización, resultado de un aumento de los escritores del «estado llano». ${ }^{19}$ En suma, estaríamos ante un proceso semejante al observado en Francia para la misma época.

En cuanto a la Nueva España, contamos con un acercamiento al perfil social (aunque sería más preciso decir «estamental») de los autores del siglo XVII. En La fortaleza docta, Chocano Mena clasificó en estamentos a 894 autores registrados por Beristáin en su Biblioteca hispanoamericana. Como era de esperar, el dominio de los regulares (franciscanos y jesuitas en la cima) resultó aplastante: solo el $24.8 \%$ eran clérigos seculares. En vista de que las instituciones eclesiásticas eran las que podían absorber a la mayoría de los graduados, los estudios y el ejercicio de las letras se supeditaron a las necesidades de las órdenes religiosas y de la Iglesia diocesana. Así, la relación entre la orientación burocrática y la vida intelectual era tan estrecha que sería "falaz separar a los 'verdaderos intelectuales' de los burócratas». ${ }^{20}$ No obstante, el que la autora se limitara a dar cifras globales (para todo el siglo XVII) impidió saber cómo se comportó la población a lo largo del mismo; también faltó aclarar qué cargos desempeñaban los eclesiásticos y a qué se dedicaban los pocos laicos que publicaron impresos. A pesar de esto, sus resultados nos advierten acerca de cambios

${ }^{18}$ La producción francesa en las décadas de 1760 y 1770 ascendió a más de 3 mil obras por año; España produjo 22,993 títulos entre 1700 y 1808. Véase López 2001: 137-138. ${ }^{19}$ Buigues 2003a: 292-300. La fuente que utilizó Buigues para realizar su análisis es la base de datos Aguil, elaborada a partir de la Bibliografía de autores españoles del siglo XVIII de Francisco Aguilar Piñal. Es importante aclarar que el catálogo de Aguilar Piñal también recoge los títulos publicados por escritores hispanoamericanos, lo cual quizás explica dicha sobrepoblación.

${ }^{20}$ Chocano 2000: 179-182. 
importantes en la República de las Letras del Seiscientos; cambios que habrían de consolidarse en la siguiente centuria.

Uno de esos primeros cambios es el aumento del número de autores, si por autores nos conformamos por ahora con la vieja convención, aceptada por los historiadores del libro, de que un autor era todo aquel que plasmaba su nombre en la portada de un impreso o bien, como aclara Darnton, que generara «una pequeńa entrada» en los repertorios bibliográficos. No obstante, en la época moderna, el concepto de autor era otro, mucho más amplio y heterogéneo: cabían tanto los creadores intelectuales de los textos como los responsables de su producción material, pasando por compiladores, comentaristas, traductores, promotores y mecenas. La paternidad de un texto no era, por lo tanto, exclusiva de creadores (pretendidamente) originales.

En el largo siglo XVIII, publicaron impresos en Nueva España 1703 autores, tanto criollos, peninsulares e individuos de otras nacionalidades que vivieron en el virreinato entre 1701 y 1821 . La nómina es menor a la que recuperó Beristáin para el mismo periodo y que, calculo, comprende alrededor de 2500 escritores. Esta diferencia se debió a que su Biblioteca incluyó también a autores de manuscritos inéditos y libros que no registró Medina, porque no sobrevivieron el paso del tiempo.

Ya entonces, para Beristáin era evidente que el tamaño de la república literaria de la Nueva Espańa era muy reducido. Darnton habla de 1187 autores franceses sólo en el año de 1757 y de 2819 en $1784 .^{21}$ Bien pudo advertir Beristáin en los repertorios europeos que llegó a consultar, que la cifra de 3687 «literatos» para los tres siglos de vida de la América septentrional era sumamente baja. De ahí, su insistencia en señalar la dificultad que había en el virreinato para acceder a las prensas tipográficas y sacar "a la luz pública» los escritos. De no ser, aseguraba, por «las dificultades, riesgos, gastos y trabajos» que padecían los autores para imprimir sus textos, la República de las Letras hubiese estado más

${ }^{21}$ Darnton 2003b: 167. De acuerdo con el estudio de Alain Viala, en el siglo XVII publicaron en Francia 5867 autores. Para el periodo de 1643-1665 contó 2200 escritores vivos, siendo la cifra máxima de 518 en el año de 1650 (Viala 1985: 240-241). 
nutrida, pues juzgaba que si algo sobraba en estas tierras era talento para la buena pluma. En efecto, hasta 1793, las únicas ciudades con imprenta (o actividad tipográfica documentada) fueron México, capital de la Nueva España, y Puebla, la segunda ciudad más importante del virreinato. ${ }^{22}$

Décadas atrás, el célebre teólogo mexicano Juan José de Eguiara y Eguren (1696-1763) —autor de la Bibliotheca Mexicana, el otro gran repertorio del siglo XVIII - se había preocupado por demostrar que el escaso número de autores de libros impresos no se debía, como se afirmaba en Europa, al supuesto atraso cultural de la América española y a la esterilidad intelectual de sus hombres de letras, sino a la falta de imprentas y a la carestía de los insumos. Él mismo se vio en la necesidad de traer de Madrid una imprenta que compró con sus propios recursos para poder imprimir su monumental Bibliotheca. Pero ni Eguiara ni Beristáin se atrevieron a criticar el sistema de privilegios y la protección que la Corona daba a los impresores y libreros peninsulares, en detrimento de los tipógrafos, los escritores y los lectores de los virreinatos americanos.

Bajo estas condiciones, con escasos talleres funcionando solo en dos ciudades, y teniendo que importar papel y tipos europeos a elevados precios, no sorprende que los autores fuesen una minoría en la Nueva España. Solo un corto número podía publicar o se interesaban en hacerlo. Sin embargo, es preciso asomarse al contexto local antes de sacar cualquier conclusión. En vísperas de la Independencia, el virreinato tenía poco más de 6 millones de habitantes, una población bastante inferior a la de Francia y España. Además, como ya se dijo, se estaba lejos de tener una industria tipográfica tan vigorosa como la europea. Francia tenía unos 250 talleres tipográficos distribuidos en 110 ciudades; y España, más de 200 a fines del siglo, repartidos en 49 localidades. ${ }^{23}$

Aunque siempre es arriesgado valorar la representatividad social de los autores sobre meros números, hay que intentarlo. No compararemos con

${ }^{22} \mathrm{Mi}$ investigación comprende la producción de ambos centros tipográficos. Muy a finales del periodo colonial, se establecieron imprentas en las ciudades de Guadalajara, Oaxaca y Veracruz; su tardía fundación y el hecho de que su producción fuese todavía muy escasa me decidió a dejarlas fuera del análisis.

${ }^{23}$ Martin 1990: 118; Buiges 2003b: 307. 
el total de la población, porque en su inmensa mayoría era analfabeta, sino con los bachilleres graduados de la Universidad de México (que ostentó el monopolio de conceder grados hasta finales del siglo XVIII). Entre 1702 y 1810, se graduaron 20,036 bachilleres. ${ }^{24}$ Los 1703 autores representarían entonces el $8.49 \%$; si esta proporción parece baja, se eleva notablemente en relación con los doctores (931), hasta subir a poco más de la mitad (54.66\%), de manera que uno de cada dos doctores tuvo acceso a la imprenta cuando menos en una ocasión. En este sentido, la caracterización que hace Rodolfo Aguirre de los graduados universitarios vale también para la mitad de los autores: un sector "con aspiraciones de privilegio y prestigio sustentado en la posesión de saberes».

Toca ahora revisar la composición socioocupacional de la población autoral. Una primera y simple clasificación por estamentos, eclesiásticos y laicos, arroja lo siguiente:

Cuadro 1. Comportamiento de la población de autores en Nueva España (1701-1821)

\begin{tabular}{cccccc}
\hline & \multicolumn{2}{c}{ Eclesiásticos* } & & \multicolumn{2}{c}{ Laicos } \\
\cline { 2 - 3 } \cline { 5 - 6 } Quinquenio & Autores & $\%$ & & Autores & $\%$ \\
\hline $1701-1705$ & 57 & 4.62 & & 14 & 3.88 \\
$1706-1710$ & 73 & 5.91 & & 16 & 4.43 \\
$1711-1715$ & 83 & 6.72 & & 23 & 6.37 \\
$1716-1720$ & 82 & 6.64 & & 15 & 4.16 \\
$1721-1725$ & 109 & 8.83 & & 17 & 4.71 \\
$1726-1730$ & 133 & 10.77 & & 24 & 6.65 \\
$1731-1735$ & 114 & 9.23 & & 19 & 5.26 \\
$1736-1740$ & 75 & 6.07 & & 13 & 3.60 \\
$1741-1745$ & 71 & 5.75 & & 19 & 5.26 \\
$1746-1750$ & 121 & 9.80 & & 20 & 5.54 \\
$1751-1755$ & 119 & 9.64 & & 12 & 3.32 \\
\hline
\end{tabular}

${ }^{24}$ Aguirre 2003: 73. 


\begin{tabular}{|c|c|c|c|c|}
\hline \multirow[b]{2}{*}{ Quinquenio } & \multicolumn{2}{|c|}{ Eclesiásticos* } & \multicolumn{2}{|c|}{ Laicos } \\
\hline & Autores & $\%$ & Autores & $\%$ \\
\hline $1756-1760$ & 132 & 10.69 & 18 & 4.99 \\
\hline $1761-1765$ & 131 & 10.61 & 15 & 4.16 \\
\hline $1766-1770$ & 104 & 8.42 & 16 & 4.43 \\
\hline $1771-1775$ & 95 & 7.69 & 16 & 4.43 \\
\hline $1776-1780$ & 89 & 7.21 & 20 & 5.54 \\
\hline $1781-1785$ & 108 & 8.74 & 34 & 9.42 \\
\hline $1786-1790$ & 111 & 8.99 & 31 & 8.59 \\
\hline $1791-1795$ & 121 & 9.80 & 29 & 8.03 \\
\hline $1796-1800$ & 70 & 5.67 & 24 & 6.65 \\
\hline $1801-1805$ & 102 & 8.26 & 25 & 6.93 \\
\hline $1806-1810$ & 112 & 9.07 & 49 & 13.57 \\
\hline $1811-1815$ & 111 & 8.99 & 45 & 12.47 \\
\hline $1816-1821$ & 155 & 12.55 & 49 & 13.57 \\
\hline Total & 1235 & 100 & 361 & 100 \\
\hline
\end{tabular}

Fuente: Elaboración propia a partir de los catálogos de Medina y de Beristáin que se citan en la bibliografía.

*Esta categoría incluye a los regulares, los seculares y a tres eclesiásticos cuya pertenencia no se pudo determinar.

Los eclesiásticos, regulares y seculares fueron en términos absolutos y relativos el grupo dominante, con poco más del 70\% (72.13) del total de autores. Vemos, pues, la preeminencia del clero cuando menos en las prensas locales, pues no sabemos cuántos novohispanos publicaron fuera del reino. No parece que la situación se modificara del siglo XVII al XVIII; sin embargo, se aprecia un aumento de los seglares, sobre todo a raíz de la crisis de 1808 y el consiguiente auge de la folletería, así como de la efímera libertad de imprenta decretada en 1810 en el marco de la convocatoria a las Cortes españolas.

A un nivel más detallado, se observa un cambio importante en la composición del segmento eclesiástico respecto del seiscientos. Tal parece 
que los efectos de la política de secularización de los Borbones y el traspaso de la administración de las parroquias indias a manos de los curas redujeron el poder de las órdenes religiosas y, en consecuencia, su preeminencia en la República de las Letras; posteriormente, la salida de los jesuitas en 1767 vendría a agudizar su declive. Desde entonces, la presencia de los seculares en las prensas locales fue en aumento. El vacío dejado por los regulares en la imprenta fue rápidamente ocupado por clérigos diocesanos. Este cambio, por demás interesante, se aprecia mejor si observamos la tendencia de la publicación de títulos nuevos.

Tendencia de obras nuevas publicadas por autores del clero regular y secular en Nueva España (1701-1821)

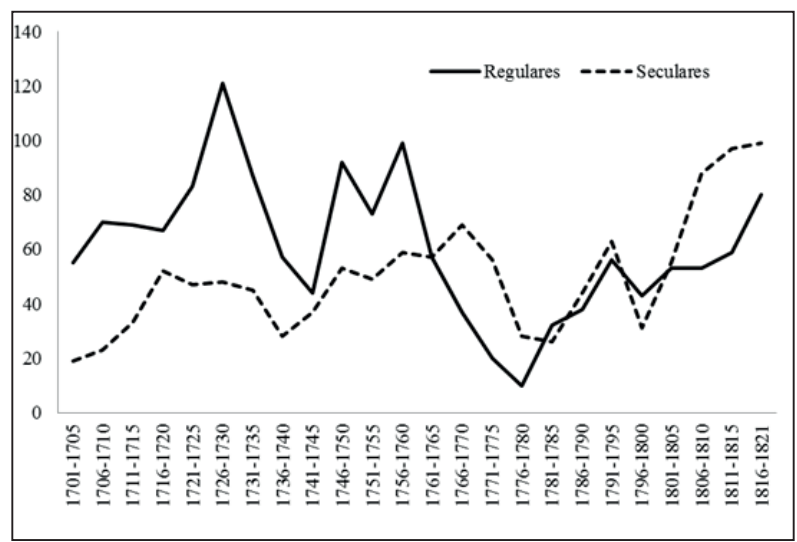

Fuente: Elaboración propia a partir de los catálogos de Medina y de Beristáin que se citan en la bibliografía.

En Nueva España, la secularización parroquial y la expulsión de la Compañía de Jesús tuvieron un impacto decisivo en el perfil de la población de autores. Falta, no obstante, estudiar con profundidad la trascendencia de este cambio en la cultura escrita e impresa, porque si bien los seculares empataron y llegaron incluso a superar a los regulares, como se aprecia en el gráfico anterior, ambos segmentos compartían, a un cierto nivel, los valores y códigos del humanismo y la escolástica. Por lo tanto, también compartían prácticas de escritura (o formas retóricas) y usos del 
impreso como, por ejemplo, la preparación de sermones ex profeso para las prensas, tema que desde hace unos años estudia Laurette Godinas. ${ }^{25}$

Ahora interesa proponer una clasificación puntual de las pertenencias institucionales/corporativas y los lugares socioocupacionales de los autores novohispanos del siglo XVIII. Los autores de las órdenes religiosas representaron en total 697 (40.86\% de 1703). Pero, dividido el siglo en dos partes, con el año de 1767 como punto de inflexión, se observa que de un periodo a otro disminuyen alrededor del $45 \% .{ }^{26}$ En cambio, el número de autores que pertenecían a la Iglesia diocesana (que en total suman 537 o $32.06 \%$ ) aumentó en $27.47 \%$ de la primera a la segunda mitad del siglo. Este grupo en ascenso está conformado, en proporciones casi iguales, por la jerarquía eclesiástica (obispos, miembros de los cabildos y curas adscritos a las catedrales) y por contingente de presbíteros sin oficio ni beneficio aparentes. Como se aprecia en el siguiente cuadro, su presencia en las prensas se multiplicó de un periodo a otro:

Cuadro 2. Posiciones socioocupacionales de los autores novohispanos (1701-1821)

\begin{tabular}{lcccccc}
\hline & \multicolumn{2}{c}{$1701-1767$} & $1768-1821$ & \multicolumn{2}{c}{$1701-1821$} \\
\cline { 2 - 7 } & Autores & Impresos & Autores & Impresos & Autores & Impresos \\
\hline Frailes mendicantes & 322 & 753 & 208 & 758 & 479 & 1,511 \\
Jesuitas & 143 & 362 & 30 & 148 & 153 & 510 \\
Órdenes hospitalarias & 13 & 22 & 4 & 10 & 15 & 32 \\
Otras órdenes & 5 & 32 & 5 & 19 & 10 & 51 \\
Monjas & 11 & 23 & 9 & 14 & 19 & 37 \\
Regulares (sin dato) & 13 & 17 & 22 & 26 & 20 & 43 \\
Prelados y capitulares & 85 & 199 & 85 & 285 & 160 & 484 \\
Curas beneficiados y titulares & 40 & 66 & 64 & 134 & 100 & 200 \\
Clérigos presbíteros & 92 & 218 & 156 & 478 & 220 & 697 \\
\hline
\end{tabular}

${ }^{25}$ Godinas se ha centrado en la amplia producción manuscrita de Eguiara y Eguren. Entre otros trabajos, véase Godinas 2017.

${ }^{26} \mathrm{El}$ número de autores desciende de 507 a 278, es decir, 45.16\% 
MORENO Ensayo de una «anatomía» de la República de las Letras. Nueva España, s. XVIII 73

\begin{tabular}{|c|c|c|c|c|c|c|}
\hline & \multicolumn{2}{|c|}{$1701-1767$} & \multicolumn{2}{|c|}{$1768-1821$} & \multicolumn{2}{|c|}{$1701-1821$} \\
\hline & Autores & Impresos & Autores & Impresos & Autores & Impresos \\
\hline Capellanes & 33 & 66 & 27 & 89 & 49 & 155 \\
\hline Presbíteros oratorianos & 17 & 42 & 25 & 118 & 31 & 160 \\
\hline Maestros de ceremonias & 5 & 16 & 10 & 56 & 14 & 72 \\
\hline Maestros músicos de capilla & 1 & 12 & 2 & 3 & 3 & 15 \\
\hline Abogados y juristas & 70 & 134 & 45 & 126 & 111 & 260 \\
\hline Funcionarios & 23 & 55 & 60 & 113 & 79 & 168 \\
\hline Médicos y cirujanos & 12 & 26 & 20 & 57 & 31 & 83 \\
\hline Militares & 6 & 7 & 24 & 48 & 30 & 55 \\
\hline Nobles indígenas & 1 & 3 & 1 & 4 & 2 & 7 \\
\hline Colegiales y universitarios & 6 & 8 & 16 & 21 & 22 & 29 \\
\hline Científicos y técnicos & 4 & 9 & 8 & 11 & 12 & 20 \\
\hline Comerciantes y mineros & 4 & 5 & 8 & 17 & 11 & 22 \\
\hline Impresores & 1 & 14 & 7 & 163 & 7 & 177 \\
\hline Oficios artísticos e intelectuales* & 8 & 14 & 15 & 115 & 23 & 129 \\
\hline Pintor de cámara & 1 & 1 & & & 1 & 1 \\
\hline Músicos & 4 & 7 & 1 & 1 & 5 & 8 \\
\hline Actores, dramaturgos & & & 2 & 6 & 2 & 6 \\
\hline Cantante de ópera & & & 1 & 1 & 1 & 1 \\
\hline Maestros y preceptores & 3 & 6 & 6 & 8 & 9 & 14 \\
\hline $\begin{array}{l}\text { Editores redactores de } \\
\text { periódicos }\end{array}$ & - & - & 5 & 99 & 5 & 99 \\
\hline Empleados & 1 & 1 & 2 & 8 & 3 & 9 \\
\hline Maestros de sastre & & & 2 & 3 & 2 & 3 \\
\hline Maestro de obras & & & 1 & 1 & 1 & 1 \\
\hline Mujeres, sin profesión & 3 & 5 & 3 & 4 & 6 & 9 \\
\hline Otros & 8 & 10 & 17 & 19 & 25 & 29 \\
\hline Total & 928 & 2119 & 852 & 2830 & 1594 & 4968 \\
\hline Sin dato & 13 & 17 & 22 & 26 & 20 & 43 \\
\hline
\end{tabular}

Fuente: Elaboración propia a partir de los catálogos de Medina y de Beristáin que se citan en la bibliografía.

* Darnton tituló a esta categoría "gremios intelectuales». Véase el anexo. 
Ahora bien, en este artículo propongo una reclasificación de los autores laicos siguiendo el modelo de Darnton para comparar el caso novohispano con el francés a partir de categorías más o menos equivalentes, sin olvidar las enormes diferencias sociales y culturales que había entre el virreinato hispánico y Francia.

En este último, los autores con oficios intelectuales (profesores, secretarios, actores, músicos, etc.) eran mayoría a finales del siglo XVIII (véase el anexo); en Nueva España seguían siendo minoría. No obstante, se trataba de personajes destacados en sus respectivos ámbitos, de individuos respetados por su elevada cultura. Los pintores, los actores y los músicos que tuvieron acceso a la imprenta local servían en la corte virreinal, el palacio arzobispal y el Coliseo, teatro principal de la capital y uno de los pocos espacios públicos de carácter secular. Los maestros, por su parte, estuvieron al frente del Nobilisimo arte de primeras letras (gremio fundado en 1601), como fue el caso de Pedro Manuel de Gama, nombrado maestro mayor a los treinta años de edad y a decir del redactor de la Gaceta de México «celebrado por los primores que con la pluma ejecutaba, y por otros, que con agudeza discurría, y al público se comunicaban». ${ }^{27}$

Es de llamar la atención que Darnton no incluyera a los autoresimpresores entre los "gremios intelectuales»; pero tampoco optó por colocarlos en el grupo de «artesanos». Siguiendo su propuesta, otorgué a los impresores novohispanos una categoría independiente. No deja de sorprender que en Francia fueran tan pocos y su producción impresa tan escasa. En Nueva Espańa, su importancia en la segunda mitad del siglo se explica por el protagonismo de Felipe Zúniga y Ontiveros y su hijo Mariano, pues ambos fueron autores de publicaciones periódicas (calendarios astronómicos y guías anuales de forasteros) que sacaron a luz en su taller tipográfico. ${ }^{28}$ No obstante, cabe aclarar que los Zúñiga fueron también matemáticos y agrimensores, por lo que bien podría colocárseles entre los "científicos y técnicos».

${ }^{27}$ Gaceta de México. Núm. 116, julio de 1737, p. 923.

${ }^{28}$ Un estudio puntual de estos impresores es el de Suárez 2019. 
También se aprecia en el cuadro que la presencia de la nobleza indígena fue excepcional, al igual que la de los artesanos y las mujeres seglares. Hacia finales de la colonia publicaron un cacique zapoteca, dos sastres, un grabador y tres mujeres, una de ellas poetisa: María Guerrero, educada en las letras desde la infancia por su padre, el preceptor de latinidad Antonio Guerrero, dueño de una escuela de gramática en la ciudad de México.

¿Cómo debemos interpretar las cifras? ¿Traducen una apertura de la cultura impresa a un sector que podría calificarse como «bajo clero»? ¿Y qué decir del modesto aumento de los autores laicos en las postrimerías del siglo? ¿Puede en verdad atribuirse a la secularización de la sociedad novohispana, a la introducción de nuevas instituciones de corte ilustrado? ¿O fue, en cambio, un reflejo difuso del reforzamiento del aparato burocrático y del control político-económico del virreinato por parte de la Corona? Si al avance de la secularización y de la Ilustración en la cultura escrita e impresa se atribuye, en buena medida, la transformación de la república de las letras en Europa occidental, ¿significa entonces que en Nueva España hubo más sombras que luces? Habrá que volver a estas y otras preguntas para seguir renovando la historiografía de la república literaria y el polémico debate sobre el impacto del reformismo borbónico, la recepción del pensamiento ilustrado y la adopción de prácticas de sociabilidad modernas entre los hombres de letras del siglo XVIII.

Por último, cabe insistir en la necesidad de incorporar otras fuentes y elementos de análisis al estudio de la República de las Letras que permitan recuperar la experiencia literaria de los autores y su realidad cultural más inmediata; situarlos en distintos espacios y en su interacción con otros letrados. Pienso aquí en un caso concreto: en los miembros de la Arcadia Mexicana, primera asociación literaria de Nueva España, que tenía entre sus filas a prebendados, frailes, abogados, etc. Para dar a conocer sus escritos, los árcades sacaron a luz el Diario de México, primer cotidiano literario de la Nueva España. ${ }^{29}$ En este espacio «virtual», se reunieron en calidad de poetas herederos de la tradición grecolatina, no de representantes de instituciones y corporaciones tradicionales. 


\section{ANEXO}

Posiciones socioocupacionales de los autores en Francia en 1757, 1769 y 1784

\begin{tabular}{|c|c|c|c|c|c|c|}
\hline & \multicolumn{2}{|c|}{1757} & \multicolumn{2}{|c|}{1769} & \multicolumn{2}{|c|}{1784} \\
\hline & Número & $\%$ & Número & $\%$ & Número & $\%$ \\
\hline Alto Clero, secular & 7 & 1 & 15 & 1 & 13 & 1 \\
\hline Alto Clero, regular & 4 & 0 & 1 & 0 & 1 & 0 \\
\hline Bajo Clero, secular & 120 & 14 & 194 & 12 & 196 & 13 \\
\hline Bajo Clero, regular & 151 & 17 & 168 & 11 & 91 & 6 \\
\hline Nobleza sin título, sin cargo & 9 & 1 & 21 & 1 & 50 & 3 \\
\hline Funcionario, alta administración & 8 & 1 & 20 & 1 & 17 & 1 \\
\hline Funcionario, militar & 38 & 4 & 85 & 5 & 109 & 7 \\
\hline Funcionario, cortes supremas & 17 & 2 & 64 & 4 & 42 & 3 \\
\hline Funcionario, altas finanzas & 8 & 1 & 23 & 1 & 1 & 0 \\
\hline Funcionario, cortes bajas & 6 & 1 & 17 & 1 & 20 & 1 \\
\hline Baja administración & 42 & 5 & 63 & 4 & 51 & 3 \\
\hline Abogado, Procurador & 67 & 8 & 169 & 11 & 162 & 11 \\
\hline Personal de las cortes & 2 & 0 & 3 & 0 & 3 & 0 \\
\hline Médico, Cirujano & 106 & 12 & 231 & 15 & 244 & 16 \\
\hline Farmacéutico & 1 & 0 & 13 & 1 & 13 & 1 \\
\hline Ingeniero/Arquitecto & 17 & 2 & 30 & 2 & 35 & 2 \\
\hline Arrendador & 3 & 0 & 2 & 0 & 0 & 0 \\
\hline Bajas finanzas & 4 & 0 & 5 & 0 & 6 & 0 \\
\hline Comerciante & 2 & 0 & 9 & 1 & 14 & 1 \\
\hline Fabricante & 1 & 0 & 2 & 0 & 0 & 0 \\
\hline Librero, Impresor & 5 & 1 & 26 & 2 & 23 & 2 \\
\hline Gremios intelectuales & 198 & 23 & 309 & 30 & 295 & 20 \\
\hline Profesor & 93 & 11 & 165 & 10 & 167 & 11 \\
\hline Maestro privado & 26 & 3 & 44 & 3 & 38 & 3 \\
\hline Reportero & 9 & 1 & 9 & 1 & 5 & 0 \\
\hline Bibliotecario & 7 & 1 & 19 & 1 & 23 & 2 \\
\hline Intérprete & 5 & 1 & 8 & 1 & 3 & 0 \\
\hline
\end{tabular}


MORENO Ensayo de una «anatomía» de la República de las Letras. Nueva España, s. XVIII 77

\begin{tabular}{|c|c|c|c|c|c|c|}
\hline & \multicolumn{2}{|c|}{1757} & \multicolumn{2}{|c|}{1769} & \multicolumn{2}{|c|}{1784} \\
\hline & Número & $\%$ & Número & $\%$ & Número & $\%$ \\
\hline Secretario & 15 & 2 & 15 & 1 & 12 & 1 \\
\hline Escribano & 2 & 0 & 8 & 1 & 8 & 1 \\
\hline Sinecura & 26 & 3 & 15 & 1 & 14 & 1 \\
\hline Actor, Personal de teatro & 8 & 1 & 15 & 1 & 21 & 1 \\
\hline Músico & 7 & 1 & 11 & 1 & 4 & 0 \\
\hline Clero Protestante & 18 & 2 & 7 & 0 & 8 & 1 \\
\hline Estudiante & 0 & 0 & 1 & 0 & 1 & 0 \\
\hline Empleado & 4 & 0 & 8 & 1 & 1 & 0 \\
\hline Tendero & 1 & 0 & 1 & 0 & 4 & 0 \\
\hline Artesano & 8 & 1 & 17 & 1 & 15 & 1 \\
\hline Sirviente & 1 & 0 & 1 & 0 & 0 & 0 \\
\hline Mujer, sin profesión & 14 & 2 & 42 & 3 & 49 & 3 \\
\hline \multirow[t]{4}{*}{ Otros } & 6 & 1 & 30 & 2 & 29 & 2 \\
\hline & 868 & 99 & 1577 & 100 & 1493 & 98 \\
\hline & \multicolumn{2}{|c|}{$73 \%$ del total: } & \multicolumn{2}{|c|}{$67 \%$ del total: } & \multicolumn{2}{|c|}{$53 \%$ del total } \\
\hline & \multicolumn{2}{|c|}{1187} & \multicolumn{2}{|c|}{2367} & \multicolumn{2}{|c|}{2819} \\
\hline
\end{tabular}

Fuente: Darnton 2003b: 172. 


\section{BIBLIOGRAFÍA}

Aguirre, Salvador. 2003. El mérito y la estrategia. Clérigos, juristas y médicos en Nueva España. Ciudad de México: Universidad Nacional Autónoma de México-Centro de Estudios Sobre la Universidad y Plaza y Valdés Editores.

Álvarez Barrientos, Joaquín. 2006. Los hombres de letras en la España del siglo XVIII. Apóstoles y arribistas. Madrid: Editorial Castalia.

Benichou, Paul. 2006. La coronación del escritor. 1750-1830. Ensayo sobre el advenimiento de un poder espiritual laico en la Francia moderna. Ciudad de México: Fondo de Cultura Económica.

Beristáin de Souza, José Mariano. 1981. Biblioteca Hispanoamericana Septentrional, ed. facs. Ciudad de México: Universidad Nacional Autónoma de México, 3 volúmenes.

Buigues, Jean-Marc. 2003a. «La sociedad de los autores». En Infantes, Víctor; François Lopez y Jean-François Botrel (eds.). Historia de la edición y de la lectura en España. 1472-1914. Madrid: Fundación Germán Sánchez Ruipérez, 292-300. . 2003b. «Evolución de la producción global». En Infantes, Víctor; François Lopez y Jean-François Botrel (eds.). Historia de la edición y de la lectura en España. 1472-1914. Madrid: Fundación Germán Sánchez Ruipérez, 301-314.

Chartier, Roger. 1991. «Los libros, ¿'hacen revoluciones?» En Chartier, Roger. Espacio público, crítica y desacralización en el siglo XVIII. Barcelona: Gedisa, 81-106.

. 1995. «El hombre de letras». En Vovelle, Michelet al. El hombre de la Ilustración. Madrid: Alianza Editorial, 153-195.

2000. «La invención del autor». En Chartier, Roger. Entre poder y placer. Cultura escrita y literatura en la Edad Moderna. Madrid: Cátedra, 89-105.

Chocano Mena, Magdalena. 2000. La fortaleza docta. Elite letrada y dominación social en México colonial (siglos XVI-XVII). Barcelona: Edicions Bellaterra.

Darnton, Robert. 2002. «Un inspector de policía organiza su archivo: la anatomía de la República de las Letras». En Darnton, Robert. La gran matanza de gatos y otros episodios en la historia de la cultura francesa. $3^{\text {a }}$ reimp. Ciudad de México: Fondo de Cultura Económica, 148-191.

. 2003a. Edición y subversión. La literatura clandestina en el Antiguo Régimen. Madrid: Turner y Fondo de Cultura Económica.

. 2003b. «La revolución literaria de 1789». En Darnton, Robert. El coloquio de los lectores. Ciudad de México: Fondo de Cultura Económica, 165-200. . 2014. «La filosofía pornográfica». En Darnton, Robert. Los best sellers prohibidos en Francia antes de la revolución. Ciudad de México: Fondo de Cultura Económica, 139-180.

Godinas, Laurette. 2017. «Estos no permito a la imprenta’ o la visión organizadora de Juan José de Eguiara y Eguren sobre su producción homilética». En Godinas, Laurette; Marina Garone Gravier e Isabel Galina Russell (eds.). De Pérgamo a la nube. Nuevos acercamientos y perspectivas a las edades del libro. Ciudad de 
México: Universidad Nacional Autónoma de México-Instituto de Investigaciones Bibliográficas, 39-49.

González González, Enrique. 2011. «Colegios y universidades. La fábrica de los letrados». En Vogeley, Nancy y Manuel Ramos Medina (coords.). Historia de la literatura mexicana: desde sus orígenes hasta nuestros dias. Volumen 3. Ciudad de México: Siglo XXI Editores y Universidad Nacional Autónoma de México, 104-127.

Griffin, Dustin. 2009. «The rise of the professional author?». En Suarez, Michael S.J. Y Michael Turner (eds.). The Book in Britain. Volumen V. Cambridge: University Press, 132-145. https://doi.org/10.1017/CHOL9780521810173.007

López, François. 2001. «Contribución al estudio de la producción impresa andaluza de 1700 a 1800». En Peña Díaz, Manuel et al. (coords.). La cultura del libro en la Edad Moderna, Andalucía y América. Córdoba: Universidad de Córdoba, 133-144.

Martin, Henri-Jean. 1990. «Une croissance séculaire». En Chartier, Roger y HenriJean Martin (coords). Histoire de l'édition française. 2. Le livre triomphant, 1660-1830. Paris: Fayard, 113-127.

Martínez Luna, Esther. 2011. El debate literario en el Diario de México (1805-1812). Ciudad de México: UNAM-Instituto de Investigaciones Filológicas.

Medina, José Toribio. 1991a. La imprenta en México (1539-1821). Ciudad de México: Universidad Nacional Autónoma de México-Instituto de Investigaciones Bibliográficas. 8 vols.

.1991b. La imprenta en la Puebla de los Ángeles. Ciudad de México: Universidad Nacional Autónoma de México-Instituto de Investigaciones Bibliográficas.

Moreno Gamboa, Olivia. 2016. «Producción impresa y autores en una ciudad episcopal: Puebla de los Ángeles, 1701-1770». En Cervantes Bello, Francisco (coord.). Libros y lectores en las sociedades hispanas: España y Nueva España (siglos XVI-XVIII). Ciudad de México: Benemérita Universidad Autónoma de Puebla-Instituto de Ciencias Sociales y Humanidades, Ediciones de Educación y Cultura, 175-201.

2018. Las letras y el oficio. Novohispanos en la imprenta. México y Puebla, siglo XVIII. Ciudad de México: Universidad Nacional Autónoma de MéxicoInstituto de Investigaciones Filológicas e Instituto Mora.

Pellisson, Maurice. 1911. Les hommes de lettres au XVIIIe siècle. Paris: Librairie Armand Colin.

Suárez Rivera, Manuel. 2019. Dinastía de tinta y papel. Los Zúñiga Ontiveros en la cultura novohispana (1756-1825). Ciudad de México: Universidad Nacional Autónoma de México-Instituto de Investigaciones Bibliográficas.

Viala, Alain. 1985. Naissance de l'écrivain. Paris: Les Éditions de Minuit.

Fecha de recepción: 4/VI/2019 Fecha de aceptación: 4/VII/2019 